\title{
The State of the Journal-Pediatric Research: The Last Seven Years-Where We Were and How Far We Have Come
}

Pediatric Research has undergone several dynamic changes during the past $7 \mathrm{y}$ as we have attempted to move the Journal forward to keep pace with the rapidly evolving scientific community. In 2003, we were given the privilege of shaping the Journal, which was successfully carried and handed to us by our many predecessors, who are stalwarts in their own right. As we took the baton from prior Chief Editors, we changed the look of the Journal to impart a scientific quality to its overall presentation. Our Journal cover focused on one scientific theme presented in each issue. We introduced the Editor's Focus Page to highlight six articles within each issue of the Journal. To help our readers quickly access their primary area of interest, we subdivided the original articles and listed the table of contents as basic, translational, and clinical investigations. We introduced various innovations to the Journal, such as rolling reviews on hot topics emerging in science, translation of discoveries, and rolling out of key clinical trials. In addition, we included mini-reviews on emerging technologies and diseases that spanned the "bench to bedside and back to bench" path. We brought in commentaries in controversial areas to highlight investigation in specific areas relevant to developmental diseases that affect children. We introduced a "Science in the News" section to help readers stay abreast of new developments and emerging discussions. Finally, an annual Review Issue, focusing on a single topic, was added to import innovation from the other disciplines, such as epigenetics, tissue engineering, infection and immunology, and the emerging field of nanotechnology, into our own discipline.

These changes, we believe, helped push forth an "out of the box" approach to investigation, thereby benefitting pediatric research. This enormous metamorphosis could not have occurred without our talented editorial board, comprising an international group of multidisciplinary members, who are actively engaged in academic research. The editorial board "think tanks," held at annual meetings of the Pediatric Academic Societies and the European Society for Pediatric Research, yielded results far greater than the sum of the individual contributions. The Journal greatly benefited from the interdisciplinary collision of ideas that originated from our editors. Along the way, we kept up with the emerging publication revolution by taking a paper-based submission and review process to one that is web based. This introduced a transparency to the submission process, whereby authors could track the processing of their manuscripts in real time. Keeping the priorities of our authors in mind, we focused on providing highquality, fair reviews with a quick turn-around-time. This revolution in the review process could not have been accomplished without the dedicated editorial board members, reviewers, and biostatisticians, who worked tirelessly to bring us a high-quality and timely finished product. Toward achieving complete transparency, we introduced various requirements for Journal sub- mission and publication, which included deposition of information in public databanks to allow for general access to experimental information and registration of clinical trials in public websites to allow for tracking of their ongoing development. On our part, we have reduced the time from acceptance to preprint, online publication, to ensure early access to accepted articles. In addition, we established the time to openaccess, published articles at $6 \mathrm{mo}$, which is half a year earlier than the National Institutes of Health mandate of 12 mo. Most importantly, we brought a sense of fairness to our editorial policies to which our entire editorial board adhered.

We are most appreciative of the many authors, who sent us their best science to review. Although not all our decisions may have gained universal approval, we strived for excellence in the Journal. Our greatest supporters are our readers, who were dedicated to tracking our Journal and its performance as we heard from you regularly regarding what you liked and what you did not like.

None of this work would have been possible without ongoing oversight and support by the Trustees of the International Pediatric Research Foundation. We witnessed the turn over in membership as mandated by the by-laws and were fortunate to interact with two sets of Trustees during our tenure.

So as autumn approaches and the leaves begin to turn colors and shed, we aspire toward the full blooms that existed during spring and summer. As we move into winter, we know that spring will come again. We have been privileged to have served as the Chief Editors during the past $7 \mathrm{y}$ and deeply honored by your trust in our ability to shape the Journal, and in a small way, shape science as it evolved. As we bid good bye to one and all, we know that we will miss the editorial work and the process of shaping the Journal that consumed a large part of our lives. As we continue to watch the face of the Journal from afar, we are confident that we have passed the baton on to a competent editorial team under the leadership of Drs. Olaf Dammann and Pierre Gressens. We have no doubt that the Journal will reach new heights in its journey under their skillful and creative oversight. We welcome and wish the new editorial team the very best and will always wish Pediatric Research well.

Sherin U. Devaskar Department of Pediatrics David Geffen School of Medicine The University of California at Los Angeles Los Angeles California 90095

Petra S. Hüppi Department of Pediatrics University of Geneva Medical School Geneva CH-1211 Switzerland 